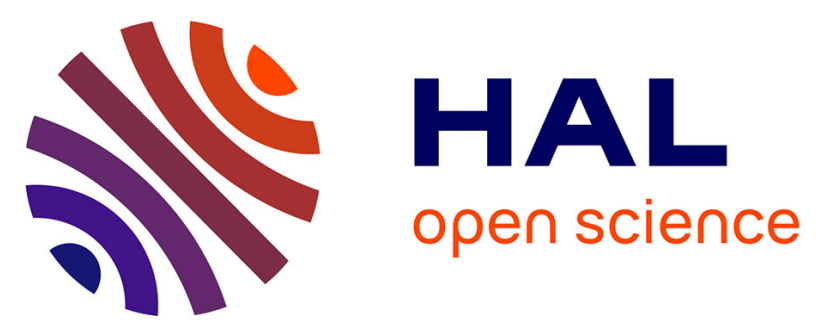

\title{
Dual-frequency operation of a vertical external cavity semiconductor laser for coherent population trapping cesium atomic clocks
}

\author{
Jessica Barrientos-Barria, Fabiola A. Camargo, Sylvie Janicot, Isabelle
} Sagnes, Arnaud Garnache, Ghaya Baili, Loïc Morvan, Patrick Georges, Gaëlle Lucas-Leclin

\section{To cite this version:}

Jessica Barrientos-Barria, Fabiola A. Camargo, Sylvie Janicot, Isabelle Sagnes, Arnaud Garnache, et al.. Dual-frequency operation of a vertical external cavity semiconductor laser for coherent population trapping cesium atomic clocks. CLEO Europe, May 2011, Munich, Germany. hal-00580003

\section{HAL Id: hal-00580003 \\ https://hal-iogs.archives-ouvertes.fr/hal-00580003}

Submitted on 25 Mar 2011

HAL is a multi-disciplinary open access archive for the deposit and dissemination of scientific research documents, whether they are published or not. The documents may come from teaching and research institutions in France or abroad, or from public or private research centers.
L'archive ouverte pluridisciplinaire HAL, est destinée au dépôt et à la diffusion de documents scientifiques de niveau recherche, publiés ou non, émanant des établissements d'enseignement et de recherche français ou étrangers, des laboratoires publics ou privés. 


\title{
Dual-frequency operation of a vertical external cavity semiconductor laser for coherent population trapping cesium atomic clocks
}

\author{
Jessica Barrientos ${ }^{1}$, Fabíola A. Camargo ${ }^{1}$, Sylvie Janicot ${ }^{1}$, Isabelle Sagnes ${ }^{2}$, Arnaud Garnache ${ }^{3}$, \\ Ghaya Baili $^{4}$, Loïc Morvan ${ }^{4}$, Patrick Georges ${ }^{1}$ and Gaëlle Lucas-Leclin ${ }^{1}$ \\ ${ }^{1}$ Laboratoire Charles Fabry de l'Institut d'Optique, CNRS, Univ Paris-Sud, Campus Polytechnique RD 128, 91127 Palaiseau Cedex, France \\ ${ }^{2}$ Laboratoire de Photonique et de Nanostructures, CNRS UPR20, Route de Nozay, 91460 Marcoussis, France \\ ${ }^{3}$ Centre d'Electronique et Micro-optoélectronique de Montpellier, CNRS UMR5507, Université Montpellier 2, 34095 Montpellier, France \\ ${ }^{4}$ Thales Research and Technology, RD 12891767 Palaiseau Cedex, France
}

Cs atomic clocks based on coherent population trapping require two phase-locked laser lines with output power in the $10-\mathrm{mW}$ range and a frequency difference of about $9 \mathrm{GHz}$ to provide the microwave interrogation. Stabilization of one laser frequency to the reference laser with a phase-locked loop and high-frequency modulation of a diode laser are the two most frequent solutions. Alternatively, dual-frequency operation of a single laser source might provide the simplest architecture. It is based on the simultaneous emission of two orthogonally-polarized laser beams sharing the same laser cavity, but with a slight anisotropy resulting in the frequency difference. The major advantage of this configuration lies in the fact that the frequency fluctuations of the two beams are strongly correlated. Such dual frequency oscillation has already been observed with rare-earth doped material lasers [1]; recently it has also been demonstrated with a $1-\mu \mathrm{m}$ vertical-external cavity semiconductor laser (VECSEL), with the benefit of low phase and intensity noise thanks to the class-A regime dynamics of VECSEL [2]. In this work, we describe the first dual-frequency operation of an optically-pumped VECSEL emitting around the $\mathrm{Cs}_{2}$ line at $852 \mathrm{~nm}$.

The semiconductor chip is grown on a $350 \mu \mathrm{m}$-thick GaAs substrate and is designed to emit at $852 \mathrm{~nm}$ [3]. The laser consists in the semiconductor active structure, a $0.5 \mathrm{~mm}$-thick $\mathrm{YVO}_{4}$ birefringent plate, a $50-\mu \mathrm{m}$ thick solid etalon and a $50 \mathrm{~mm}$ radius of curvature concave output mirror with transmission of $0.5 \%$ at $852 \mathrm{~nm}$. The $\mathrm{YVO}_{4}$ plate forces the laser emission on two cross-polarized spots, distant from $50 \mu \mathrm{m}$ on the active chip while the etalon guarantees a stable single-frequency operation of each polarization and the tunability of the laser emission. The pump source is $2 \mathrm{~W}$-broad-area laser diode coupled into a $100 \mu \mathrm{m}$ diameter, NA $=0.22$, multimode fiber emitting at $670 \mathrm{~nm}$. It is focused on a $100 \mu \mathrm{m} \times 130 \mu \mathrm{m}$-elliptical spot on the structure. With a cavity length of $\sim 49 \mathrm{~mm}$ (free spectral range of $3 \mathrm{GHz}$ ), the laser cavity waist is $80 \mu \mathrm{m}$ in the structure.

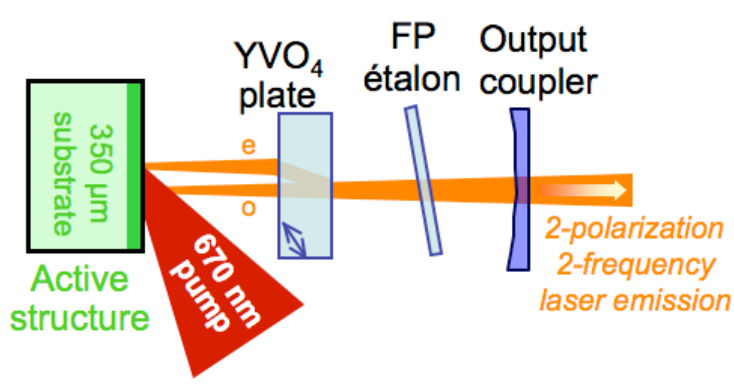

Fig. 1 : Experimental setup of the dual-frequency VECSEL; o,e stands respectively for the ordinary and extraordinary polarized beams.

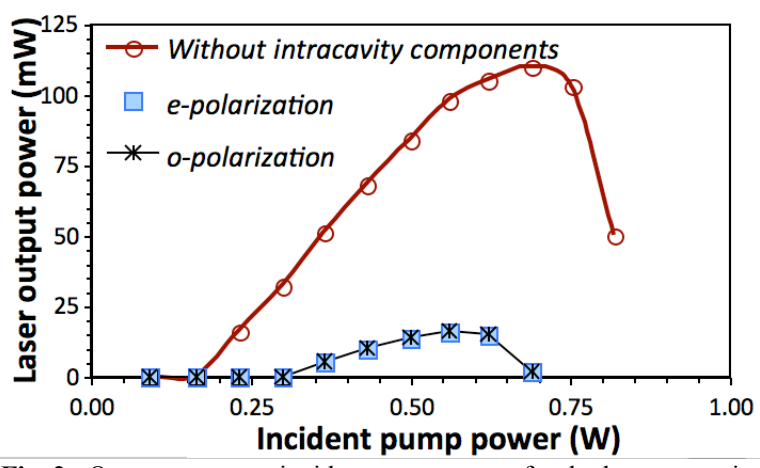

Fig. 2 : Output power $v s$ incident pump power for the laser operating around $\mathrm{T}=15^{\circ} \mathrm{C}$ without (circle) and with the birefringent plate and the etalon on each polarization.

Without any intracavity element, the laser output power reaches $110 \mathrm{~mW}$, limited by the strong thermal roll-over of the active structure (Fig. 2). With the birefringent plate and the intracavity Fabry-Perot etalon, the laser emission is purely single-frequency on each polarized beam, with almost equal output power of $16 \mathrm{~mW}$ in each (Fig. 2). The strong decrease of the total output power is mainly due to the high losses introduced by the etalon. The frequency difference $\Delta v$ is determined by the free spectral range of the laser cavity and by the intracavity phase anisotropy. In this preliminary experiment, $\Delta v$ can be adjusted from $\sim 100 \mathrm{MHz}$ to $\sim 40 \mathrm{GHz}$ with the alignment of the intracavity components. Further work to precisely control $\Delta v$ with an intracavity electro-optic modulator and to tune it around the $9 \mathrm{GHz}$ microwave transition is under progress.

\section{References}

[1] M. Alouini et al, "Dual tunable wavelength Er,Yb:glass laser for terahertz beat frequency generation", IEEE PTL 10, 1554 (1998)

[2] G. Baili et al, "Experimental demonstration of a tunable dual-frequency semiconductor laser free of relaxation oscillations", Opt. Lett. 34, $3421(2009)$

[3] B. Cocquelin et al, "Tunable Single-frequency operation of a diode-pumped Vertical-External Cavity Laser at the Caesium $\mathrm{D}_{2}$ line", App. Phys. B 95, 315 (2009)

Acknowledgments : The authors acknowledge the financial support of the Agence Nationale de la Recherche under the ANR-07BLAN-0320-03 program. They are grateful to E. Götz and B. Sumpf from Ferdinand-Braun-Institut für Höchtstfrequenztechnik (Germany) for the red high-power broad area laser diode. 